\title{
Reporting Violent Victimization to the Police: A Focus on Black, White, Asian and Hispanic Adolescent Victims
}

\author{
Callie Marie Rennison ${ }^{*}, 1$, Angela R. Gover ${ }^{1}$, Stacey J. Bosick ${ }^{2}$ and Mary Dodge ${ }^{1}$ \\ ${ }^{1}$ School of Public Affairs, University of Colorado Denver, Denver, Colorado 80217-3364, USA \\ ${ }^{2}$ Department of Sociology, University of Colorado Denver, Denver, Colorado 80217-3364, USA
}

\begin{abstract}
Explorations of patterns of why and when citizens report crime to police are an important area of study in the field of criminology and criminal justice. Initial National Crime Survey data suggest that a substantial proportion of crime went unreported to the authorities (i.e., law enforcement reports as reflected by the Uniform Crime Reports). The purpose of this study is to enhance our understanding about reporting violence against adolescents to the police. This research examines the extent and nature of reporting violence against juveniles to the police, and specifically focuses on how reporting differs between white, black, Asian and Hispanic adolescents. This area is important to investigate to ascertain whether all groups have equal access to the benefits of the Criminal Justice system. Additionally, understanding why adolescent victims or their agents fail to engage the criminal justice system in the wake of a violent victimization is relevant to the development of policy addressing weaknesses in the police response and the particular vulnerabilities of minority victims and their communities.
\end{abstract}

Keywords: Reporting, violent victimization, adolescents, police, race, ethnicity.

The decision to report a violent victimization to the police involves a variety of complex structural and cultural factors. While it is important to identify factors related to police reporting to better inform policy it is equally essential to understand why incidents are not reported to the police. Knowing the reasons why violence is not always reported to the police is the first step in the development of educational programs that inform citizens about police and community resources. One of the primary purposes of this type of interaction with the community is to develop trust with law enforcement, a process that requires time and commitment.

How and why crime is reported to the police is not a new area of research within the field of criminology and criminal justice [1-8]. Initial National Crime Survey data suggests that a substantial proportion of crime went unreported to the authorities (i.e., law enforcement reports as reflected by the Uniform Crime Reports). Early studies maintained that calling the police was related to the seriousness of the incident: the more serious the offense the more likely the victim was to call the police [9]. Gottfredson and Hindelang [10] also attributed the probability of police reporting to characteristics of the incident (e.g. seriousness) rather than characteristics of the victim or offender. Other studies discovered that the decision to report a crime to the police depends on the costs versus incentives [11]. A person is less likely to report when there is the potential for embarrassment, when the victim wants to protect the offender, when the victim is afraid of the offender, if the victim was engaged in illegal activities at the time of the

\footnotetext{
*Address correspondence to this author at the School of Public Affairs, University of Colorado Denver, Campus Box 142, 1380 Lawrence Street, Suite 525R, P.O. Box 173364, Denver, Colorado 80217-3364, USA; Tel: 303-315-2813; Fax: 303-315-2229;

E-mail: callie.rennison@ucdenver.edu
}

incident, and opportunity costs. Early on it was suggested that many people calling the police do so because they have no other alternatives, and that wealthier victims may rely on their financial and support networks when seeking assistance due to victimization [10].

As indicated above, reporting violence to the police has been a significant and important focus of prior research. There is a void in the literature, however, of studies that examine reporting of violence against juvenile and adolescent victims. The majority of the literature available on juvenile and adolescent reporting is limited to crime committed at school. The Department of Justice found, for example, that 255,000 juveniles between the ages of 12 and 18 experienced serious violent crime while they were at school or while they were in route to and from [12]. While addressing violence and safety in schools is paramount in terms of policy, the available estimates fail to shed light on violent crime against juveniles in the general population. Estimates of crime occurring at schools cannot be generalized to crime committed against juveniles of the same age in the general population, and especially among those who do not attend school. Consequently, it is important to examine the extent of reporting and issues related to why adolescents do not report violent crime in order to have a baseline measure for the population. Research has developed an understanding of why victims report crime to the police and why they do not; this research, however, is based on samples of all persons - a sample overwhelmingly composed of adults. Currently, little information is available on whether the reasons why adolescent victimization is reported or not are similar to reasons why adult victimization is or is not reported to law enforcement. Before comparisons can be made between juveniles and adults regarding victimization reporting, it is first necessary to empirically examine 
differences between groups of juveniles. That is a purpose of this research.

\section{BACKGROUND LITERATURE}

\section{Reporting Crime to the Police}

Previous research estimated that about half of all violent crime victimizations do not come to the attention of law enforcement [11, 13-16]. Rand and Catalano [17] discovered that reporting rates have not improved over time but have actually remained stable since 1967 . However, using data from the National Crime Survey (NCS) and the National Crime Victimization Survey (NCVS), Baumer and Lauritsen [18] refuted this notion by examining trends in reporting crime to the police between 1973 and 2005. Their findings indicated that rates of crime reporting to the police have in fact improved over time. Specifically, significant increases in reporting were found for male and female violent crime victims, violence committed by perpetrators who were strangers and those known to victims, and victimization experiences reported by members of racial and ethnic minority groups. The results from this study are particularly important since the these sources (NCS and NCVS) represent data collected on the national level that can identify the extent to which crime occurring in society does not come to the attention of the police [18]. An analysis of NCVS trend data by Hart and Rennison [14] found that $43 \%$ of violent crime victimization was reported between 1992 and 1999 , but increases in reporting were found for 2000. Fortynine percent of violent crime victimizations were reported to police in 2000 [14]. Similar findings were noted by Tarling and Morris [19] in their analysis of the British Crime Survey for crime reported to the police between 1994 and 2007. Results indicated that citizen reporting of violent crime had increased over time, but the trend in property crime reporting over time had declined.

\section{Factors that Influence Reporting Crime to the Police}

Seriousness of the Incident. In 1972, the first and largest nationally representative crime survey implemented in the U.S. was the National Crime Survey (NCS) by the Department of Justice and Bureau of Census. The data revealed that a large proportion of crime was going undetected by the police. Early studies indicated that the most serious cases of victimization had the highest likelihood of being reported to the police [9-11, 15-16]. Later work based on victim surveys showed that the most important factor in deciding whether or not to call the police was the serious nature of the event [20]. Tarling and Morris [19] examined data from the British Crime Survey and found that the seriousness of the crime was the most important predictor of crime being reported to the police. The seriousness of the incident appears to increase the incentive for victims to report. Gottfredson and Gottfredson [11] purported that victims were more likely to report crime to the police when incentives are high and costs are low. Cost factors were considered to be public embarrassment, desire to protect offender, fear of reprisal, engagement in illegal activities, and opportunity costs. The combination of knowing the offender and experiencing a serious victimization is the main reason victims fear reprisal and therefore do not report to formal sources [21].
Respondent and Incident Characteristics. Some of the literature that focuses on victimization reporting behavior examines factors that impact one's decision to call the police. Findings reported by Kruttschnitt and Carbone-Lopez [22], for example, suggested that respondent and incident characteristics significantly impact the likelihood of calling the police among a sample of general female crime victims. Analogously, Gartner and Macmillan [23] discovered that individual factors (e.g., age, relationship type) as well as incident characteristics (e.g., physical injury, weapon use) were significantly related to lifetime victimization experiences being reported to the police. The work conducted by Avakame, Fyfe, and McCoy [24] placed a heavier emphasis on the impact that extralegal factors (race, gender, wealth, education) have on general crime victim's decisions to report crime to the police. According to Rennison [25], violence against female victims is more likely to be reported to the police than is violence against male victims, violence against black victims is more likely to be reported to the police than is violence against white victims, and violence against older victims is more likely to be reported to the police than is violence against younger victims [14].

The Relationship Between the Victim and Offender. One of the most commonly studied variables in terms of its impact on reporting behavior is the relationship between the victim and the offender $[1,6,16,23,26-29]$. Research suggests that victimization by someone known to the victim is less likely to be reported to police compared to victimization by a stranger [23]. This is true of studies with samples comprised of both intimate partner violence victims and general crime victims. However, this finding is not universal. Felson, Messner, and Hoskin [7] did not find the relationship between the victim and offender to significantly impact reporting behavior among a general sample of crime victims.

Failure to Report. According to early research using the National Crime Survey (NCS) data, multivariate models estimated among a sample of general crime victims indicated that fear of reprisal was the most common reason victims who knew their offenders gave for not reporting to the police [21]. In fact, women viewed calling the police to be a dangerous response to victimization because they feared retaliation. Similarly, research indicates that fear of reprisal is most commonly a factor in cases of intimate partner violence, but this is also a reason victims of crime in general do not report the incident to the police. The role that fear plays in crime reporting among juveniles is of particular concern, especially if the person is someone they know. More recent research indicates that because the victim viewed the violence as private/personal in nature, they were unlikely to contact the police [14]. While there are several reasons why victimization may go unreported, it is unclear what these reasons are for juveniles and whether they differ from the population in general.

\section{Limited Work Examining Reporting Behavior Within Groups}

While a significant amount of research has focused on citizen reporting behaviors, and while exceptions can be found [25] this area of inquiry has not delved into reporting 
behavior for specific minority groups, even among Hispanics, the fastest growing minority group in the nation. Early descriptive reports suggested that differences did not exist between Hispanics and non-Hispanics in terms of the overall level of violence reported to the police [30-37]. Adding to this descriptive information Hart and Rennison [14] examined reporting behavior for overall violence and specifically for rape/sexual assault, assault (simple and aggravated), and robbery. Bivariate findings suggested that the only difference in violence reporting among Hispanics and non-Hispanics was for robbery, with robbery against non-Hispanic victims being more likely to be reported than robbery against Hispanic victims. These findings were in line with Baumer's [2] multivariate analysis of the relationship between socioeconomic disadvantage and reporting violence to the police in that robbery committed against a non-Hispanic was more likely to be reported to the police than robbery committed against a Hispanic. Reporting differences were not found for simple or aggravated assault for Hispanics and non-Hispanics. When looking at reporting sexual assault among female college students, however, data from the National College Women Sexual Victimization Study suggested that Hispanic female college students were not more or less likely to formally report sexual victimization [38]. Focusing on victimization against juveniles provides additional insight into why crime victimization is not being reported to law enforcement. And, without an understanding as to the extent to which juvenile reporting fails to occur efforts to increase juvenile victimization reporting are hindered. Furthermore, specific policies may be needed if it is determined that certain groups of individuals under-report crime at higher rates than others. Increasing rates of reporting violence against juveniles to the police establishes a practice that would ideally lead to more accurate crime rates in general, and especially over time.

\section{Current Study}

The primary purpose of this research is to enhance our understanding about reporting violence against juveniles to the police. Research on reporting violence has a long and rich history, yet it seems that a focus on juveniles has been neglected except for a growing interest in school violence. Given the well-documented importance of reporting violence, gaining a better understanding the extent of violence against juveniles that is reported (or not) to the police is essential. A secondary goal of this research is to understand differences in reporting among juvenile victims. That is, we investigate how reporting of violence against white, black, Asian and Hispanic juvenile populations differs. ${ }^{1}$

We address this important topic based on three research questions (RQ):

\footnotetext{
${ }^{1}$ The NCVS treats races and Hispanic origin as two concepts. For ease of presentation, we use the term "race" instead of "race/Hispanic origin" to refer to the groups being considered. We use both concepts to develop the groups compared in this research: non-Hispanic white, non-Hispanic black, non-Hispanic Asian, non-Hispanic American Indian, non-Hispanic multiple race, and Hispanic (any race). To further simplify presentation, we use the terms: white, black, Asian, American Indian, multiple race and Hispanic in this research.
}

- RQ1: What is the extent of police reporting for violence against black, white, Asian and Hispanic juveniles?

- RQ2: Research indicates that predictors of police reporting differ by groups. Thus, we next turn our attention to examining what are the predictors of police reporting for violence against black, white, Asian and Hispanic juveniles and how do they differ?

- $\quad$ RQ3: In order to gain a deeper understanding of adolescent reporting issues, we turn to the nature of police reporting. Specifically we address who reports the victimization? In addition, we investigate why the violence was or was not reported to the police.

\section{METHODOLOGY}

\section{Data}

To address the research questions, this analysis utilizes National Crime Victimization Survey (NCVS) data. NCVS data are collected using a stratified, multistage cluster design and are publicly available through the National Archive of Criminal Justice Data [39-40]. These data come from a sample of housing units and groups quarters (including college dormitories) in the United States and the District of Columbia. In each sampled unit, all persons age twelve or older are interviewed, either in person or on the phone, at six month intervals for a three year period. Data come from an annual average of about 200,000 interviews with respondents in about 90,000 households reflecting response rates ranging from 91 to 96 percent for households and 84 to 94 percent for individuals. NCVS methodology provides data representative of the non-institutionalized population of persons age twelve or older in the United States [40-41].

The NCVS are well-suited for a study on police reporting of violence against juveniles with a focus on victim's race. First, the large sample size with accompanying small sampling error of the NCVS allows investigations of relatively small populations (such as juveniles). Second, NCVS data include an extensive range of situational characteristics of violent victimizations including weapon presence, bystander presences, victim/offender relationship, victim injury, and location of the incident. Third, NCVS data include violent victimizations regardless of whether they were or were not reported to the police. Research is clear that reporting is related to characteristics such as the victim's age, race, weapon presence, and gender making an examination of only reported violence problematic [14].

The NCVS, like all data, are subject to limitations. The NCVS covers a limited set of violent victimizations: rape/sexual assault, robbery, aggravated assault and simple assault. Other sorts of violence such as homicide, kidnapping, and arson are not included in these analyses. Second, these analyses do not reflect the experiences of those age eleven or younger. And finally, because the NCVS is based on a household sample, it cannot offer information on juveniles who are homeless or residing in institutions. While imperfect, the NCVS provides an excellent opportunity to examine reporting of violence against juveniles to the police.

\section{Sample}


To examine police reporting of violence against juveniles, this study focuses on non-fatal violent victimizations which include attempted and completed rape, sexual assault, robbery, aggravated assault, and simple assault. Standard NCVS definitions are utilized. The data are restricted to individuals in the NCVS who are age 17 or younger at the time of the interview because the focus of this research is violence perpetrated against juveniles. The years of data used in the analyses begin in 1992 and end in 2005 . $^{2}$ The data begin in 1992 as this is the first year of NCVS following a major redesign. The aggregation of pre- and post-redesign data is not recommended. ${ }^{3}$ The analyses exclude victimizations occurring in 2006 and more recently because of several significant methodological changes that took place in the NCVS beginning in 2006. These changes include the elimination of CATI, a sample reduction, and the inclusion of unbounded surveys in the NCVS. These methodological changes resulted in what amounts to a break in series [42]. Restricting our analyses on 1992 to 2005 victimizations against persons age 12 through 17 results in 7,963 unweighted violent victimizations.

\section{Measures}

Reporting to the Police. The purpose of this research is to present estimates of reporting to the police as well as examining predictors of police reporting. In the models focused on predictors of police reporting, whether a violent victimization was reported to the police serves as the dependent variable (reported $=1$; not reported $=0){ }^{4}$

Victim's Race. This variable is measured using four categories: white, black, Asian and Hispanic. ${ }^{5}$ To create this variable, two NCVS questions are used: Hispanic origin and race of the victim. In the NCVS, a victim is coded "Hispanic" if they self-describe as Spanish, Hispanic, Latino, Mexican-American, Chicano, Mexican, Puerto Rican, Cuban, Central or South American (Spanish Countries) or some "other" Spanish origin. If a respondent responds "don't know" regarding their Hispanic origin, they are asked if they have a parent or grandparent who is "Spanish, Hispanic or Latino." If they do, they are coded "Hispanic." If a respondent describes themselves has having multiple ethnic origins and one is Spanish, Hispanic or Latino, they are coded "Hispanic." All others respondents are coded "nonHispanic." In the NCVS, the race of a victim is ascertained by the field representative who asks the respondent how they describe themselves. Race of the victim is not recorded in

\footnotetext{
${ }^{2}$ Regression models use data beginning in quarter 3 of 1993 . This marks the first quarter in which pseudostratum and secucode (standard error computation unit code) variables were included on the NCVS data file. These variables in conjunction with the 'person weight' on the file enables analyses that take into account the complex sample design of the NCVS (e.g., the survey weighted regression functions in STATA). All other analyses use data beginning in 1992.

${ }^{3}$ See Rennison and Rand (2007) for additional information on the redesign. Data gathered in 1992 was administered with a split-sample. That is, half the data gathered during 1992 utilized the older methodology while half utilized redesigned methodology. These analyses only use post-redesign data through 2005. Data gathered in is based on major methodological changes that make them incomparable to previous years (Truman \& Rand, 2010).

${ }^{4}$ For greater detail about all variables used in this research, please see the Appendix.

${ }^{5}$ Information about American Indians and multiple race victims are available upon request. This information is not included in this research as the sample size for these groups proved too small in most instances.
}

the NCVS based on the field representative's observation even if the victim's race may seem obvious to them.

Control Variables. Several victim characteristics identified in extant research as influential on police reporting are included in the multivariate models as controls [2, 14, 38]. ${ }^{6}$ For example, findings indicate that violence against females, older victims, and the poor is more likely to be reported to the police. These are accounted for by variables identified as Victim's gender, Victim's age, and Annual HH income. Research also demonstrates that violence in suburban and rural areas and against persons living in owned dwellings is associated with greater police reporting. Therefore, these relevant correlates are included using variables identified as MSA of victim and Own/Rent.

Characteristics of the offender have also been shown to influence the likelihood that violence is reported to the police. For example, research shows that the number of offenders, the age, gender, and the race of the offender is related to likelihood of police reporting. Thus, the following models include variables identified as Offender's race, Offender's age, and Offender's gender. Offender characteristics are based on the victim's perception of the offender. While this likely introduces some error, research into victim perceptions suggests that the error is insignificant. Hindelang [43] compared perceived offender characteristics (race and age) from the National Crime Survey to offender characteristics recorded in police reports and found little disagreement between the two data sources (e.g., over 96\% agreement for race).

Incident characteristics are important to consider as well. The severity of violence is one of the most widely agreed upon predictors of whether the police are contacted [9-11, 15-16]. In general, the more serious the violence, an injured victim, and the presence of a weapon are associated with greater police reporting. These correlates are accounted for using variables named Type of violence, Weapon Presence and Injury. Finally, extant research notes that the victim and offender relationship, number of offenders, the presence of bystanders and the location of the violence are associated with likelihood of police reporting [44]. Based on these findings, the analysis includes Victim/offender relationship, Third party presence, Number of offenders, and Location of Incident in the models as controls.

\section{Analytic Strategy}

Two analytic strategies are utilized. The first strategy focuses on comparisons of estimates from NCVS data. Due to the complex sample design of the NCVS, comparisons of estimates using techniques that assume simple random sampling are inappropriate. Thus, all comparisons of estimates in the present research are tested using formulae designed specifically by the Bureau of the Census for use with the NCVS. These tests, referred to as "SIGMA," use generalized variance function constant parameters to calculate variance estimates, standard errors, and confidence intervals. These values are used to assess whether the differences in observed statistics could be due to chance

\footnotetext{
${ }^{6}$ For a detailed description and coding of all variables, please see the Appendix.
} 
(sampling error) or if it is highly improbable that differences are due to sampling error.

The regression models presented also required special attention due to the complex design of the NCVS methodology. Failure to account for this complex sample design leads to biased standard errors and inflated t-statistics. To adjust for the sample design of the NCVS, regression models were estimated using STATA's survey weighting regression procedures [45]. One drawback with adjusting for the complex sampling is that traditional goodness-of-fit diagnostics cannot be estimated for these models [45]. Thus, model fit statistics reported are based on parallel regressions which do not account for sample design effects because such statistics are not available using the survey regression procedures [45]. All analyses utilize the appropriate weights available on the file to account for non-response and differential probability of selection.

\section{RESULTS}

Before addressing the three specific research questions, this section describes the data used in the analyses. Findings show that a large proportion of violence against juveniles is not reported to the police $(69 \%)$. Sixty-seven percent of the victimized juveniles are white, $17 \%$ are black, and $13 \%$ are Hispanic. On average, victims were 14.5 years old, in the eighth grade and male $(61 \%)$. Half of all victimizations occurred in a suburban area $(50 \%)$, on school property $(43 \%)$, in the presence of bystanders $(75 \%)$ by an unarmed $(74 \%)$, known offender $(64 \%)$, and resulted in no injury to the victim $(72 \%){ }^{7}$

The first research question focuses on the extent of police reporting for violence against black, white, Asian and Hispanic juveniles. Table 1 indicates that reporting of violence against juveniles is universally low. Only $29 \%$ of violence against juveniles age 12 to 17 is reported to the police. The second finding indicated in Table $\mathbf{1}$ is some variation in the rate of reporting among the victim groups. Violence against black juveniles compared to white juveniles is significantly more likely to be reported to the police (35\% and $28 \%$ respectively, $\mathrm{p}<.05)$. Violence against black juveniles is more likely to be reported than is violence against Asian juveniles (35\% and 23\% respectively, $\mathrm{p}<.05)$. No other apparent differences are statistically different at the $\mathrm{p}<.05$ level.

Table 1. Percentage of Violent Victimizations Against Juveniles Reported and Not Reported to the Police by Victim's Race

\begin{tabular}{|c|c|c|c|c|}
\hline Reported or Not & White & Black & Asian & Hispanic \\
\hline \hline Police notified & 27.7 & 35.1 & 23.4 & 31.3 \\
\hline Police not notified & 70.6 & 63.0 & 76.6 & 67.1 \\
\hline Don't know & 1.7 & 1.9 & 0.0 & 1.6 \\
\hline Total & 100.0 & 100.0 & 100.0 & 100.0 \\
\hline
\end{tabular}

Our second research question is what are the predictors of police reporting for violence against black, white, Asian and Hispanic juveniles and how do they differ? To address this question, a series of logistic regressions were estimated.
Findings of these models are presented in Tables $\mathbf{2}$ and $\mathbf{3}$. The first important finding is that the four victim groups (white, black, Asian and Hispanics) shared some predictors of reporting violence to the police. Violence committed by an offender age 30 or older (compared to an offender less than age 18) is significantly more likely to be reported to the police. Second, a victimization in which the victim is injured is significantly more likely to come to the attention of the police than are victimizations involving an uninjured victim. This is the case for both minor and serious injuries. Third, when a violent victimization involves multiple offenders, it is more likely to be brought to the attention of the police than is violence committed by a single offender. And finally, when violence occurs in or on school property versus to being in or near the victim's home, it is significantly less likely to be reported to the police.

These models show that some predictors of police reporting identified in the literature are not important predictors for some juvenile victim groups. Previous findings characterizing the population in general do not necessarily represent juveniles in each racial category. For example, extant literature indicates that violence against a female is more likely to be reported to the police than is violence against a male. In contrast, gender is not a significant predictor of police reporting for Asians or Hispanic juvenile victims. A second example is found with age. Age of the victim has also long been noted as an important correlate of police reporting; the older the victim, the more likely the police are to be notified. On the contrary, findings indicate that among blacks and Asians, age is not a significant predictor of police reporting. Third, the severity of violence is repeatedly described as the single most important predictor of police reporting. Results in Tables $\mathbf{2}$ and $\mathbf{3}$ indicate that this is not the case for all juvenile victim groups. Among whites, robbery is more likely to be reported than is simple assault. In contrast, rape/sexual assault and aggravated assault are no more likely to be reported than is simple assault. Findings also show that for blacks, Asians and Hispanics, the type of crime is not a significant predictor of police reporting. A fourth example focuses on weapon presence. Weapon presence is a long held predictor of reporting to the police in that if a weapon is brandished during a violent incident, the police are more likely to be contacted. Again, Tables $\mathbf{2}$ and $\mathbf{3}$ show this to be the case for some victim groups and some weapons only. Among white and black juvenile victims, a victimization involving a firearm is more likely to be reported than one involving no weapon. In contrast, for Asian and Hispanic juveniles, weapon presence is not a predictor of police reporting. Finally, extant research generally suggests that violent victimization by an unknown offender is more likely to be reported than violence by a known offender. Findings presented here indicate the opposite and that this relationship does not hold for all victim groups. Findings show that for white juvenile victims, an offense committed by a known offender is significantly more likely to be reported than is one committed by a stranger. For black, Asian and Hispanic victims, whether the offender was a stranger or known was not a predictor of police reporting.

${ }^{7}$ Descriptive statistics are not shown due to space considerations. Descriptive statistics are available from the authors upon request. 
Table 2. Survey Weighted Logistic Regression Model Predicting Reporting Violence Against Juveniles to the Police, White and Black Victims

\begin{tabular}{|c|c|c|c|c|c|c|c|c|c|c|}
\hline \multirow[b]{2}{*}{ Variables } & \multicolumn{5}{|c|}{ White (Unweighted $n=4,864$ ) } & \multicolumn{5}{|c|}{ Black (Unweighted n=946) } \\
\hline & b & SE & & p-Value & $\operatorname{Exp}(b)$ & b & SE & & p-Value & $\operatorname{Exp}(b)$ \\
\hline \multicolumn{11}{|l|}{ Victim characteristics } \\
\hline Female Victim & 0.23 & 0.11 & * & 0.04 & 1.26 & 0.53 & 0.22 & $*$ & 0.02 & 1.71 \\
\hline Victim's Age & 0.08 & 0.02 & $*$ & 0.00 & 1.08 & 0.06 & 0.05 & & 0.24 & 1.07 \\
\hline Annual household income & -0.04 & 0.01 & $*$ & 0.01 & 0.97 & -0.06 & 0.03 & $*$ & 0.02 & 0.94 \\
\hline Rented household & 0.00 & 0.10 & & 0.96 & 1.00 & -0.44 & 0.21 & $*$ & 0.04 & 0.65 \\
\hline \multicolumn{11}{|l|}{ MSA of Victim } \\
\hline Urban (reference) & & & & & & & & & & \\
\hline Suburban & -0.02 & 0.09 & & 0.81 & 0.98 & 0.18 & 0.20 & & 0.38 & 1.20 \\
\hline Rural & -0.16 & 0.13 & & 0.22 & 0.85 & 0.38 & 0.35 & & 0.27 & 1.46 \\
\hline \multicolumn{11}{|l|}{ Offender characteristics } \\
\hline \multicolumn{11}{|l|}{ Offender's Gender } \\
\hline Male (reference) & & & & & & & & & & \\
\hline Female & -0.01 & 0.13 & & 0.95 & 0.99 & -0.25 & 0.22 & & 0.26 & 0.78 \\
\hline Both & 0.66 & 0.24 & * & 0.01 & 1.94 & 0.18 & 0.53 & & 0.74 & 1.19 \\
\hline Don't know & -0.57 & 0.51 & & 0.26 & 0.56 & -1.41 & 0.76 & & 0.07 & 0.24 \\
\hline Missing data & 0.12 & 0.76 & & 0.87 & 1.13 & -3.11 & 1.63 & & 0.06 & 0.04 \\
\hline \multicolumn{11}{|l|}{ Offender's Race } \\
\hline White (reference) & & & & & & & & & & \\
\hline Black & -0.08 & 0.12 & & 0.47 & 0.92 & -0.82 & 0.30 & $*$ & 0.01 & 0.44 \\
\hline Other & -0.15 & 0.14 & & 0.29 & 0.86 & -0.57 & 0.43 & & 0.18 & 0.56 \\
\hline Mixed race/ethnicity group & -0.25 & 0.18 & & 0.17 & 0.78 & -1.31 & 0.53 & $*$ & 0.01 & 0.27 \\
\hline Don't know & 0.01 & 0.21 & & 0.97 & 1.01 & -0.49 & 0.54 & & 0.37 & 0.61 \\
\hline \multicolumn{11}{|l|}{ Offender's Age } \\
\hline Less than 18 (reference) & & & & & & & & & & \\
\hline 18 to 29 & 0.38 & 0.12 & $*$ & 0.00 & 1.47 & 0.59 & 0.33 & & 0.08 & 1.80 \\
\hline 30 or older & 1.35 & 0.15 & $*$ & 0.00 & 3.84 & 1.60 & 0.34 & $*$ & 0.00 & 4.93 \\
\hline Mixed age group & 0.16 & 0.15 & & 0.30 & 1.17 & 0.37 & 0.31 & & 0.25 & 1.44 \\
\hline Unknown & 0.00 & 0.28 & & 0.99 & 1.00 & 0.93 & 0.49 & & 0.06 & 2.53 \\
\hline \multicolumn{11}{|l|}{ Incident characteristics } \\
\hline \multicolumn{11}{|l|}{ Type of violence } \\
\hline Simple assault (reference) & & & & & & & & & & \\
\hline Rape/sexual assault & 0.44 & 0.24 & & 0.06 & 1.56 & -0.41 & 0.57 & & 0.47 & 0.66 \\
\hline Robbery & 0.30 & 0.14 & $*$ & 0.03 & 1.35 & -0.19 & 0.32 & & 0.56 & 0.83 \\
\hline Aggravated assault & 0.29 & 0.23 & & 0.21 & 1.33 & 0.47 & 0.42 & & 0.26 & 1.60 \\
\hline \multicolumn{11}{|l|}{ Weapon presence } \\
\hline No weapon (reference) & & & & & & & & & & \\
\hline Firearm & 0.57 & 0.26 & $*$ & 0.03 & 1.77 & 0.83 & 0.40 & $*$ & 0.04 & 2.29 \\
\hline Knife & 0.10 & 0.25 & & 0.69 & 1.11 & 0.22 & 0.45 & & 0.62 & 1.25 \\
\hline Other & 0.02 & 0.23 & & 0.94 & 1.02 & -0.05 & 0.45 & & 0.90 & 0.95 \\
\hline
\end{tabular}


(Table 2) contd.....

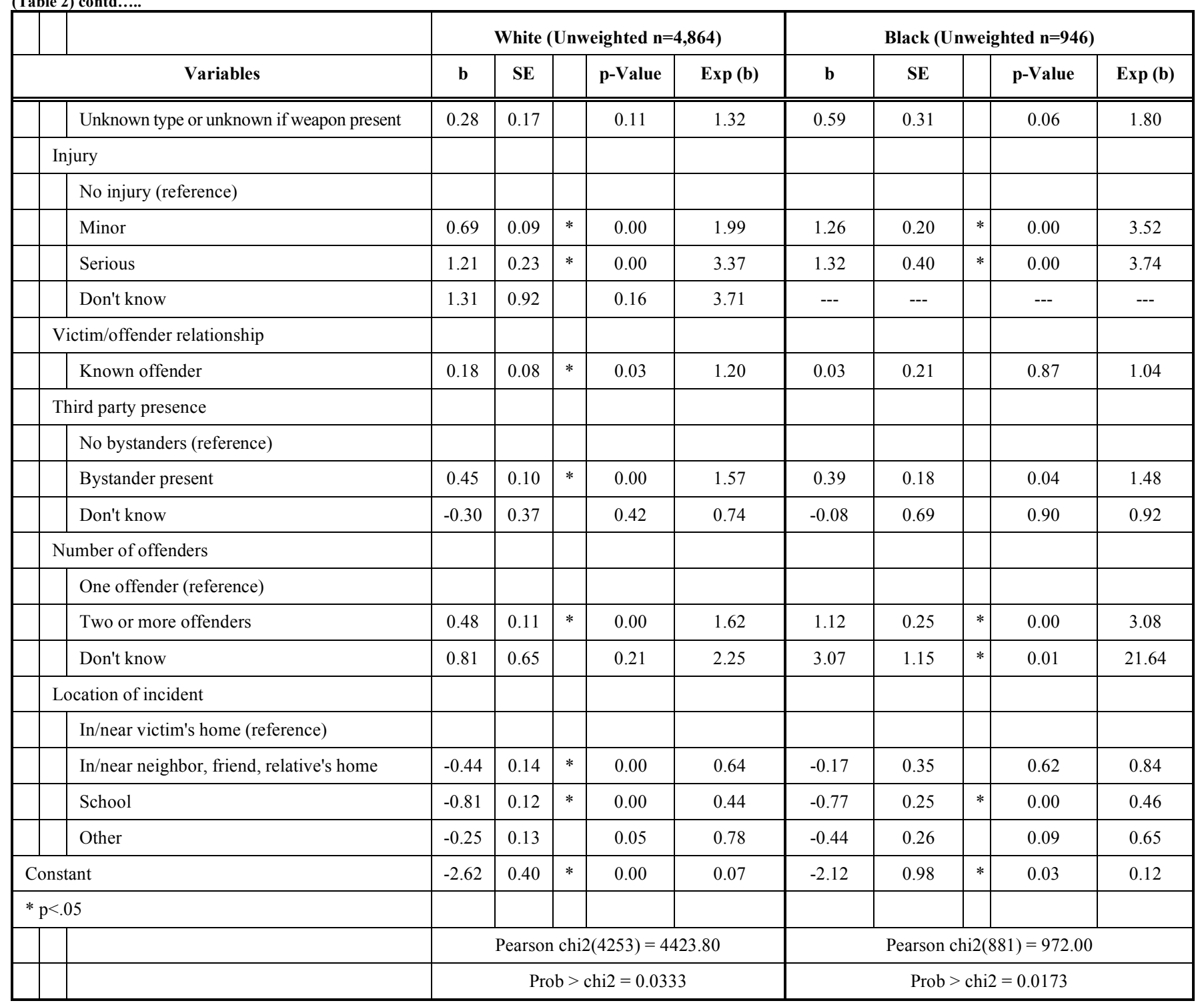

Findings presented in the table identify unique predictors for each victim group. For instance, violence against Hispanics juveniles in a suburban area is less likely to be reported than is similar violence in urban areas. This predictor is not shared with the other victim groups. The likelihood that violence against white and black juveniles is reported decreases as annual household income increases. Income is not a predictor for Asian and Hispanic victims. Violence against white juveniles committed by a group of males and females is more likely to be reported than violence committed by males. This predictor is unique to white juveniles. Violence against black juveniles is less likely to be reported when the offender is black or the victimization was committed by a group of offenders of differing races (versus white). Again, this predictor is unique to black juvenile victims only. Finally, violence against white juveniles is more likely to be reported when bystanders are present. This predictor is significant for white victims only.

The third research task focuses on understanding the nature of police reporting. We first address who reported the victimization to the police. Results offered in Table 4 indicate variation in who reported the victimization to the police by victim groups. The data indicate that when youth are victimized, the incident is most commonly reported by the victim's household member, followed by the victim his or herself. For the most part, this is consistent across race. When white and black youth are victimized the incident is most likely to be self-reported ("victim") or reported by the victims' household members. These are reversed when Hispanics are victimized, with "other household member" being most common. Asian victims most commonly report the incident themselves. Of the juvenile victim groups, Asians are least likely to have a household member report on their behalf and the most likely to have "some official other than the police" or "someone else" to report the incident.

Finally, our third task focuses on understanding the nature of police reporting. We first address who reported the victimization to the police. Percentages indicating reasons were subjected to testing to ascertain if they statistically differed from one another. Any differences or similarities in percentages discussed here are based on these tests. Thus, while some estimates may appear to differ in the table, they 
Table 3. Survey Weighted Logistic Regression Model Predicting Reporting Violence Against Juveniles to the Police, Asian and Hispanic Victims

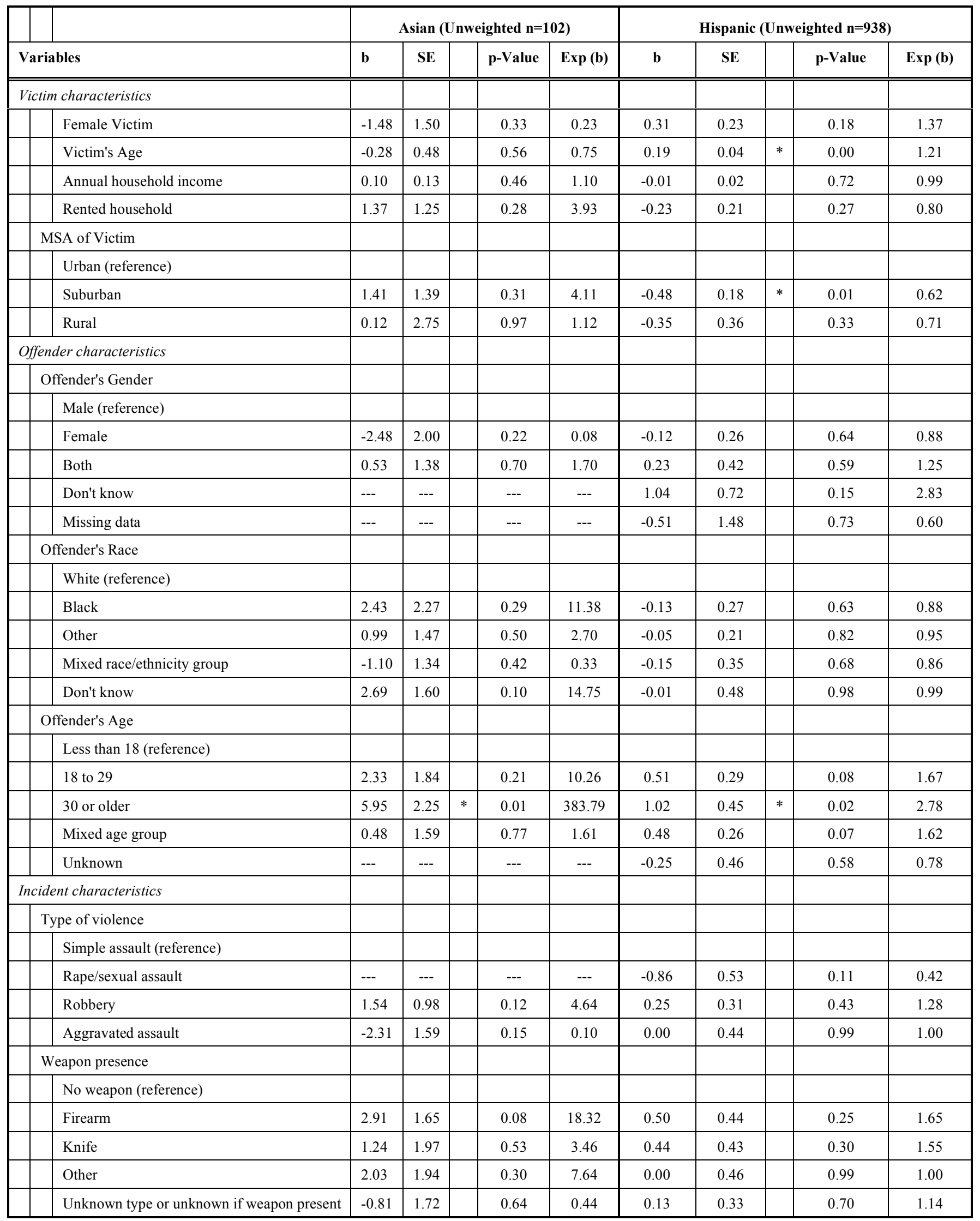


(Table 3) contd.....

\begin{tabular}{|c|c|c|c|c|c|c|c|c|c|c|c|}
\hline \multirow{2}{*}{\begin{tabular}{l|l|} 
& $\mid$ \\
& \\
Variab
\end{tabular}} & \multirow{2}{*}{ bles } & \multicolumn{5}{|c|}{ Asian (Unweighted $n=102$ ) } & \multicolumn{5}{|c|}{ Hispanic (Unweighted n=938) } \\
\hline & & b & SE & & p-Value & $\operatorname{Exp}(b)$ & b & SE & & p-Value & $\operatorname{Exp}(b)$ \\
\hline \multicolumn{12}{|c|}{ Injury } \\
\hline \multicolumn{12}{|c|}{ No injury (reference) } \\
\hline & Minor & 1.94 & 0.91 & $*$ & 0.04 & 6.93 & 0.65 & 0.19 & $*$ & 0.00 & 1.92 \\
\hline & Serious & --- & --- & & --- & --- & 1.67 & 0.44 & $*$ & 0.00 & 5.31 \\
\hline & Don't know & --- & --- & & --- & --- & --- & --- & & --- & --- \\
\hline \multicolumn{12}{|c|}{ Victim/offender relationship } \\
\hline & Known offender & 0.59 & 0.76 & & 0.44 & 1.80 & 0.13 & 0.17 & & 0.47 & 1.13 \\
\hline \multicolumn{12}{|c|}{ Third party presence } \\
\hline \multicolumn{12}{|c|}{ No bystanders (reference) } \\
\hline & Bystander present & 0.44 & 1.59 & & 0.79 & 1.55 & 0.32 & 0.20 & & 0.11 & 1.37 \\
\hline & Don't know & --- & --- & & --- & --- & 0.72 & 0.59 & & 0.23 & 2.05 \\
\hline \multicolumn{12}{|c|}{ Number of offenders } \\
\hline \multicolumn{12}{|c|}{ One offender (reference) } \\
\hline & Two or more offenders & 2.37 & 0.86 & $*$ & 0.01 & 10.74 & 0.24 & 0.22 & & 0.28 & 1.26 \\
\hline & Don't know & --- & --- & & --- & --- & 0.65 & 1.29 & & 0.62 & 1.91 \\
\hline \multicolumn{12}{|c|}{ Location of incident } \\
\hline \multicolumn{12}{|c|}{ In/near victim's home (reference) } \\
\hline & In/near neighbor, friend, relative's home & -0.60 & 2.02 & & 0.77 & 0.55 & -0.24 & 0.34 & & 0.47 & 0.78 \\
\hline & School & -0.83 & 1.21 & & 0.49 & 0.43 & -0.56 & 0.23 & $*$ & 0.01 & 0.57 \\
\hline & Other & -0.40 & 1.06 & & 0.71 & 0.67 & -0.64 & 0.25 & $*$ & 0.01 & 0.53 \\
\hline \multicolumn{2}{|c|}{ Constant } & -1.85 & 4.97 & & 0.71 & 0.16 & -4.03 & 0.81 & $*$ & 0.00 & 0.02 \\
\hline & & \multicolumn{4}{|c|}{ Pearson chi2 $(71)=82.55$} & & \multicolumn{5}{|c|}{ Pearson chi $2(870)=932.60$} \\
\hline & & \multicolumn{4}{|c|}{ Prob $>$ chi $2=0.1644$} & & \multicolumn{5}{|c|}{ Prob $>$ chi $2=0.0692$} \\
\hline
\end{tabular}

may or may not differ statistically. Results offered in Table $\mathbf{5}$ indicate some variation in who reported the victimization to the police. Turning first to white juvenile victims, findings show statistically equal percentages of white victims stated that the "victim" or some "other household member" contacted the police following the violence. These two categories contact the police most frequently. In contrast, black juvenile victims stated that the police are most likely to learn of a violent victimization against a black juvenile from some "other household member." This group was statistically more likely to contact the police than any other when a black juvenile was victimized. When considering Asian juvenile victims, results indicate that the police were likely to learn about the victimization from the "victim," some "other household member," "some official other than the police" and "someone else." That is, these four groups were statistically equal in terms of police reporting. And finally, the police are most likely to learn of violence against a Hispanic juvenile directly from the "victim," some "other household member" or "some official other than the police." Again, statistically equal percentages were noted between the "victim," some "other household member" or "some official other than the police."
We next turn to the reasons victims stated the victimization was reported to the police. Results in Table $\mathbf{5}$ indicate almost perfect uniformity for reporting violence to the police across victim groups. In general, victims who offered a reason for why the victimization was reported to the police stated it was done in an effort to stop or prevent the violence from reoccurring. This was the reason most frequently provided by white, black and Hispanic juvenile victim groups. The reasons given for reporting the victimization of Asian youth diverged from the reasons given when other youth were victimized. According to Asian juvenile victims, these crimes were most commonly reported in an effort to recover property. Though not the most frequently cited reason for why the violence was reported, efforts on the part of the reporters of "improve police surveillance of [their] home/area" also stands out as unique to cases involving Asian victims.

The last exploration concerns why victimizations were not reported to the police. Table $\mathbf{5}$ shows some minor variation between the victim groups. As was the case above, these percentages have been subjected to testing to ascertain whether apparent differences are statistically different. Among white juvenile victims, the most frequently cited 
Table 4. Percentage Distribution of Who Reported the Violence to the Police, by Victim's Race

\begin{tabular}{|c|c|c|c|c|}
\hline \multirow{2}{*}{ Who Reported the Violence } & \multicolumn{3}{|c|}{ Non-Hispanic } & \multirow{2}{*}{ Hispanic } \\
\hline & White & Black & Asian & \\
\hline Victim & 27.2 & 25.0 & 29.6 & 27.8 \\
\hline Other household member & 30.4 & 35.4 & 19.3 & 24.8 \\
\hline Some official other than police & 16.7 & 17.8 & 25.5 & 20.3 \\
\hline Someone else & 17.7 & 15.1 & 19.4 & 17.5 \\
\hline Police at crime scene & 3.5 & 4.3 & 0.0 & 4.7 \\
\hline Other & 4.6 & 2.5 & 6.3 & 4.8 \\
\hline Total & 100.0 & 100.0 & 100.0 & 100.0 \\
\hline
\end{tabular}

Note: "Other" includes when the offender was a police officer, unspecified other means, and missing data.

Table 5. Percentage Distribution of Reasons for Reporting to the Police Among Cases which were Reported, by Victim's Race

\begin{tabular}{|c|c|c|c|c|}
\hline \multirow{2}{*}{ Reasons for Reporting } & \multicolumn{3}{|c|}{ Non-Hispanic } & \multirow{2}{*}{ Hispanic } \\
\hline & White & Black & Asian & \\
\hline Stop/prevent incident from happening again & 28.0 & 26.4 & 15.1 & 25.1 \\
\hline Needed assistance after incident & 2.0 & 3.4 & --- & 3.4 \\
\hline Recover property & 3.1 & 16.3 & 36.2 & 9.4 \\
\hline Collect insurance & 0.3 & --- & --- & --- \\
\hline Protect victim $/ \mathrm{hh}$ from more crime by offender & 22.6 & 10.0 & 17.3 & 16.7 \\
\hline Prevent offender from committing against others & 7.5 & 6.2 & 15.0 & 5.4 \\
\hline Punish offender & 4.1 & 3.4 & --- & 3.2 \\
\hline Catch offender & 1.3 & 1.1 & --- & 4.4 \\
\hline Improve police surveillance of home/area & 0.4 & --- & 16.4 & 1.2 \\
\hline Duty to tell police & 2.1 & 4.2 & --- & 4.3 \\
\hline Other Reason & 4.4 & 2.5 & --- & 8.3 \\
\hline Do not know if crime was reported to police & 23.3 & 23.5 & --- & 16.7 \\
\hline Missing data & 0.9 & 2.8 & --- & 2.0 \\
\hline Total & 100.0 & 100.0 & 100.0 & 100.0 \\
\hline
\end{tabular}

reason not to report the violence to the police was because it was "reported to some other official." Black juvenile victims most frequently stated that the violence was not reported to the police since it had been reported to "some other official" and because it was a "private/personal matter." A single reason was most often noted by Asian victims as to why the violence went unreported. That is, Asian juveniles noted that the violence was unreported because it was minor or unsuccessful in nature. And finally, Hispanic victims most frequently stated that the most common reason that violence was unreported because it was both minor/unsuccessful and it had been reported to some "other official." Unfortunately, it is unclear from the data who these other officials are, and whether or not they are notifying the police.

\section{DISCUSSION}

Criminologists and criminal justice practitioners are well aware of the "dark figure of crime," which refers to the substantial portion of crime that goes unreported. These findings from the NCVS suggest that this "dark figure" looms larger among juveniles than adults. The current research strikingly demonstrates that less than a third of the victimizations experienced by juvenile delinquents in the United States are reported to police. Closer to half of victimizations are officially reported in the population at large [14]. Victimization of juveniles of all races was more likely to be reported under some conditions: when the victim suffered an injury, when the offender was age 30 or over or there were multiple offenders, and when the crime occurred in or on school property. 
Table 6. Percentage Distribution of Reasons for Not Reporting Incident to the Police among those Cases that were Not Reported, by Victim's Race

\begin{tabular}{|c|c|c|c|c|}
\hline \multirow{2}{*}{ Why Not Reported } & \multicolumn{3}{|c|}{ Non-Hispanic } & \multirow{2}{*}{ Hispanic } \\
\hline & White & Black & Asian & \\
\hline Private/personal matter & 19.4 & 20.1 & 12.7 & 15.9 \\
\hline Minor/unsuccessful crime, small/no loss, recovered property & 20.4 & 16.9 & 22.8 & 23.1 \\
\hline Not clear a crime or harm was intended & 2.7 & 1.6 & 6.1 & 1.8 \\
\hline Police knew too late & 0.1 & 0.4 & 0.0 & 0.1 \\
\hline Could not recover or identify property & 0.1 & 0.4 & 0.0 & 0.4 \\
\hline Could not identify offender, lack of proof & 1.4 & 3.2 & 1.8 & 2.5 \\
\hline Did not want to get offender in trouble w/law & 1.7 & 2.0 & 2.4 & 1.3 \\
\hline Advised not to report crime to police & 0.1 & 0.0 & 0.9 & 0.0 \\
\hline Afraid of reprisal by offender or others & 2.6 & 4.5 & 6.8 & 6.4 \\
\hline Too inconvenient to take time & 1.7 & 1.8 & 2.1 & 2.3 \\
\hline Other reasons for not reporting & 12.3 & 14.4 & 15.1 & 14.2 \\
\hline Do not know why did not report crime & 2.3 & 2.6 & 1.8 & 1.6 \\
\hline Total & 100.0 & 100.0 & 100.0 & 100.0 \\
\hline
\end{tabular}

An investigation into the reasons juveniles give for and against reporting victimization, offers a fuller picture of why this difference exists. In contrast to extant literature, few juveniles cited "fear of reprisal by the offender." In fact, one of the most common explanations for reporting juvenile victimization to police was to protect the victim and the victim's household from further crime by the offender. This suggests this rationale may be more specific to cases involving women in domestic violence situations. Studies based on the general population have discovered that victimization is underreported because those involved viewed the incidents as a private or personal. Our findings based on juveniles are consistent with this. However, juveniles also offer that they reported the incidents to officials other than the police or that the incidents were minor, unsuccessful or resulted in little to no property loss. Further insight may be gained from identifying and understanding the role of "other officials" in youth violence. Still, both suggest that the greater proportion of unreported victimization of juveniles relative to the unreported victimization of adults is largely due to the greater proportion of minor incidents they experience.

The data also show police reporting to differ significantly by race. Violence against black juveniles had the highest probability of being reported, which is consistent with earlier work that included cases of adult victimization [14]. Offenses involving black victims were significantly more likely to be reported than offenses against white or Asian respondents. This is a matter ripe for further investigation given blacks overrepresentation in the criminal justice system and the fact that black youth are most likely to be victimized by other black youth.

The findings also suggest that several of the conditions found in previous research to increase the likelihood of reporting do not hold across race of victim. In many ways, extant findings are confirmed among white victims. The probability that a crime will be reported is known to be higher when a female is victimized and increase with the age of the victim. Yet our findings suggest that the relationship with gender only holds for black and white adolescent victims, while the relationship with age only holds for whites and Hispanics. The literature further suggests that some characteristics of the violent incident help to predict whether it will be reported. More severe crimes and crimes involving a weapon are more likely to result in police notification. Type of crime failed to predict police reporting, except among whites who were especially likely to report robberies. Use of a weapon by the offender was significant, but only when white and black youth were the victims. Finally, though exceptions exist [46], the literature indicates that violent crimes in which the offender is unknown to the victim are more likely to be reported than those in which the offender and victim know one another. Whether the offender was known to the victim was insignificant in our findings, except for whites among whom the opposite relationship was discovered. Police notification was more likely when white youth were victimized by known offenders. 
The fact that conditions found in the general population are most consistent with white victims is not surprising given that whites constitute the majority of the general population. Over half $(54.5 \%)$ of the youth victimized and represented in the NCVS are white. Yet this calls attention to the fact that studies fail to differentiate victims by race are missing differences that may prove critical in understanding how minorities interact with the criminal justice system.

Our findings suggest it may be especially interesting to focus some study on cases involving Asian victims. These cases most differ from cases in which victims were of other races in terms of who reports these incidents and why. Victimizations involving Asian victims were less likely than cases involving victims of other races to be reported by household members and more likely to be reported by those described ambiguously as "other" - either other officials or other people. They were also more likely than other cases to be reported in an effort to recover property or improve policing of their community.

\section{CONCLUSION}

The benefits of efforts to promote crime reporting to law enforcement are numerous and can provide police and lawmakers with accurate information for policy decisions [22-23]. Gartner and Macmillan [23] identified several areas of concern related to underreporting victimization. They noted that a systemic under-reporting of certain types of crimes interferes with endeavors to provide equal protection. Equally important is the missed opportunity to reduce chances of further victimization by the same offender. The failure to report crime, especially among juveniles, establishes limits on how effectively police officers operate and may impact funding of community policing efforts. Establishing trust between citizens and law enforcement, however, is rife with difficulties.

The challenge for law enforcement is to equally protect and serve people from all backgrounds, though the complexities of policing multicultural communities are numerous [48]. Problematic encounters with law enforcement among different ethnic and racial groups are well documented. Past experiences by minority groups related to immigration laws, a lack of knowledge about the legal system, and perceived unresponsiveness by law enforcement influence decisions to contact authorities. For many immigrants the decision to report may be tied to their experiences with more corrupt departments in their home countries that engage in brutality and repressive military regimes [48].

While the majority of United States citizens embrace the protective power of law enforcement, much of which is determined by trust in police, numerous studies show that African Americans and Hispanics remain suspicious of police [47-52]. Findings from the current study indicate that juveniles represent a unique group that remains reluctant to report victimization to law enforcement. Taylor, Turner, Esbensen, and Winfree [53] discovered that negative attitudes of juveniles toward law enforcement were common, particularly among racial groups. In their study, African American and Hispanic juveniles overwhelming agreed that police officers were dishonest. The current research, however, shows a high rate of reporting among black victims. Future research is needed to fully determine the underlying reason for possible changes in perceptions among certain minority community members, particularly juvenile populations.

The high rates of reporting victimization within school environments suggests that community policing efforts can be successful with juveniles. In many cases, school resource officers are able to establish relationships with students, which results in greater trust. These efforts are less likely to occur in the community as police departments struggle with decreasing resources and support for programs designed build relationships with citizens. Although the current work offers a limited perspective on juvenile reporting, it appears that reporting by "other" to "other officials" is indicative of the lack of trust among juveniles and law enforcement. Overall, community policing programs represent an avenue to improved crime detection and reporting [54].

The current study is limited in its ability to full explore the dynamics of juvenile and minority victimization to the police. The NCVS data offer a starting point for exploration but have delineated explanatory power. Further, qualitative research with community members and police officers would provide a more in-depth picture of the reasons and motivations associated with juveniles' failure to report victimization. The results of this study show a need for further investigation into violent victimization in a particularly vulnerable population.

\section{ACKNOWLEDGEMENT}

None declared.

\section{CONFLICT OF INTEREST}

None declared.

\section{APPENDIX}

\section{VARIABLES}

Dependent Variable

Reporting to the Police

Independent Variable

Victim's Race

\section{DESCRIPTION}

Measurement of whether the police were notified is based on the NCVS question: "Were the police informed or did they find out about this incident in any way?" Descriptive information on this variable is presented using three categories: reported to the police (by anyone), not reported, and don't know. In the multivariate analyses, cases in which the victim was uncertain if the crime was or was not reported $(1.7 \%$ of juvenile victimizations) are excluded. Thus, logistic regression models are based on coding in which $0=$ not reported and 1 = reported.

\footnotetext{
The victim's race is self-described and uses the following four categories: Non-Hispanic white (referred to as "white"), Non-Hispanic black ("black"), Non-Hispanic Asian ("Asian"), and Hispanic (may be of any race; referred to as "Hispanic"). In multivariate models, "white" serves as the excluded reference category. The NCVS also gathers information on two additional groups: Non-Hispanic
} 
American Indian, and persons of multiple races. While these groups are described in Table I (descriptives) there were two few victims in each of these categories to be included in the other analyses.

\section{Control Variables}

Victim's Gender

Victim's Age

Annual HH Income

Own/Rent

MSA of Victim

Offender's Gender

Offender's Race

Offender's Age

Type of Violence
To account for the relationship between gender and reporting victimization, a dichotomous variable where $0=$ male, and $1=$ female is used in the analyses.

Age is measured using a continuous variable ranging from 12 years to 17 years.

This concept is measured using 14 annual household income categories of unequal size. These categories include, from lowest to highest: Less than $\$ 5,000, \$ 5,000$ to $\$ 7,499, \$ 7,500$ to $\$ 9,999, \$ 10,000$ to $\$ 12,499, \$ 12,500$ to $\$ 14,999, \$ 15,000$ to $\$ 17,499, \$ 17,500$ to $\$ 19,999, \$ 20,000$ to $\$ 24,999$, $\$ 25,000$ to $\$ 29,999, \$ 30,000$ to 34,999 , $\$ 35,000$ to $\$ 39,999, \$ 40,000$ to $\$ 49,999, \$ 50,000$ to $\$ 74,999, \$ 75,000$ and over. Similar to other research, this variable is treated as continuous in nature.

Owning or renting one's home is accounted for by a dichotomous measure in which $0=$ owns and $1=$ rents.

Three dichotomous measures are included to represent location: urban, suburban, and rural. Urban location represents the reference category.

To account for offender's gender, several dichotomous variables are utilized: male, female, a combined know and missing data. "Male" refers to a single or a group of male offenders. Similarly, "female" refers to a single or a group of female offenders. When the victim could not tell if the offender was coded with "don't know." "Male" is the excluded category in the multivariate models.

Five dichotomous variables are used to describe the offender's race. The reference category is White (reference category). The remaining categories include: black, other, group of multiple race/ethnicities, and don't know.

To account for offender's age, a series of five dichotomous indicators are used: less than 18 years, $19-29$ years of age, 30 years of age or older, mixed age group of offenders, and don't know. Offender age 18 or less serves as the excluded reference category.

To account for different types of violent victimization, four dichotomous variables are constructed and used: simple assault (reference category), rape/sexual assault, robbery, and aggravated assault. Each category group of both males and females, don't male or female, the victimization was

includes attempted and completed acts.

Weapon Presence

Injury

Victim/Offender Relationship

Third party Presence

Number of Offenders

Location of Incident
A series of five dichotomous variables are used to account for the presence and type of weapon used in a victimization: no weapon (reference), firearm, other, knife, and don't know.

Injuries sustained by the victim are included with four dichotomous variables: no injury, minor injury, serious injury, and don't know. Minor injuries include bruises, black eyes, cuts, scratches, swelling, or any unknown injury resulting in less than two of hospitalization. Serious injuries includes completed rape, broken bones, lost teeth, internal injuries, loss of consciousness and any unknown injury resulting in two or more days of hospitalization. No injury serves as the reference category.

One dichotomous variable is used to identify the victim and offender's relationship: stranger and known. The variable representing a stranger relationship serves as the reference group.

The presence or absence of bystanders is measured using three dichotomous variables: no bystanders (reference), bystander present, and a "don't know" category.

The number of offenders is measured using three dichotomous variables: one offender (reference), two or more offenders, and a "don't know" category.

A series of three dichotomous measures are used to account for the location of the incident. : In or near the victim's home, in or near the home of a victim's friend, family, or neighbor, and some other location. In or near the victim's home serves as the reference group.

\section{REFERENCES}

[1] Bachman R. The factors related to rape reporting behavior and arrest: New evidence from the national crime victimization survey. Crim Justice Behav 1998; 25: 8-29.

[2] Baumer EP. Neighborhood disadvantage and police notification by victims of violence. Criminology 2002; 40: 579-616.

[3] Baumer EP, Felson R., Messner SF. Changes in police notification for rape 1973-2000. Criminology 2003; 41: 841-872.

[4] Block R, Block CR. Decisions and data: The transformation of robbery incidents into official robbery statistics. J Crim Law Criminol 1980; 71: 622-636.

[5] Clay-Warner J, Burt CH. Rape reporting after reforms: Have times really changed? Violence Against Women 2005; 11: 150-176

[6] Du Mont J, Miller K, Myhr TL. The role of "real rape" and "real victim" stereotypes in the police reporting practices of sexually assaulted women. Violence Against Women 2003; 9: 466-486.

[7] Felson RB, Messner SF, Hoskin AW, Deane G. Reasons for reporting and not reporting domestic violence to the police. Criminology 2002; 40: 617-647.

[8] Felson RB, Pare PP. The reporting of domestic violence and sexual assault by nonstrangers to the police. J Marriage Fam 2005; 67: 597-610.

[9] Skogan WG. Citizen reporting of crime: Some national panel data. Criminology 1976; 13: 35-549.

[10] Gottfredson MR, Hindelang MJ. Study of the behavior of law. Am Sociol Rev 1979; 44; 3-17. 
[11] Gottfredson MR, Gottfredson DM. Decision making in criminal justice $\left(2^{\text {nd }}\right.$ ed.). New York NY: Plenum 1988.

[12] Office for Victims of Crime. Reporting school violence. Legal Series Bulletin \#2. Washington DC: U.S. Government Printing Office, 2002.

[13] Catalano S. Criminal victimization 2004. Washington DC: U.S. Government Printing Office 2005.

[14] Hart TC, Rennison CM. Reporting crime to the police: 1992-2000. Washington DC: U.S. Government Printing Office 2003.

[15] Laub JH. Ecological considerations in victim reporting to the police. J Crim Justice 1981; 9: 419-430.

[16] Skogan WG. Reporting crimes to the police: The status of world research. J Res Crime Delinq 1984; 21; 113-137.

[17] Rand MR, Catalano S. Criminal victimization 2006. Washington DC: U.S. Government Printing Office 2007.

[18] Baumer EP, Lauritsen JL. Reporting crime to the police 19732005: A multivariate analysis of long-term trends in the National Crime Survey (NCS) and National Crime Victimization Survey (NCVS). Criminology 2010; 48: 131-186.

[19] Tarling R, Morris K. Reporting crime to the police. Br J Criminol 2010; 50: 474-490.

[20] Birkbeck C, Gabaldon LG, LaFree G. The decision to call the police: A comparative study of the United States and Venezuela. Int Crim Justice Rev 1993; 3: 25-43.

[21] Singer SI. The fear of reprisal and the failure of victims to report a personal crime. J Quant Criminol 1988; 4: 289-302.

[22] Kruttschnitt C, Carbone-Lopez K. Customer satisfaction: Crime victims' willingness to call the police. Ideas in American Policing 2009; 12: 1-15.

[23] Gartner R, Macmillan R. The effect of victim-offender relationship on reporting crimes of violence against women. Can J Criminol 1995; 19: 393 -429.

[24] Avakame EF, Fyfe JJ, McCoy C. "Did you call the police? What did they do?" An empirical assessment of Black's theory of mobilization of law. Justice Q 1999; 16: 765-792.

[25] Rennison CM. An investigation of reporting violence to the police: A focus on Hispanic victims. J Crim Justice 2010; 38: 390-399.

[26] Feldman-Summers S, Norris J. Differences between rape victims who report and those who do not report to a public agency. J Appl Soc Psychol 1984; 14: 562-573.

[27] Greenberg MS, Ruback RB. After the crime: Victim decision making. New York: NY 1992

[28] Laub JH. Patterns of criminal victimization in the United States. In: Davis RC, Lurigio AJ, Skogan WG, Eds. Victims of crime, Sage 1997; pp. 23-49.

[29] Lizotte AJ. The uniqueness of rape: Reporting assaultive violence to the police. Crime and Delinquency 1985; 31: 169-190.

[30] Catalano S. Criminal victimization 2003. Washington DC: U.S. Government Printing Office 2004.

[31] Rennison CM. Criminal victimization 1998: Changes 1997-1998 with trends 1993-1998. Washington DC: U.S. Government Printing Office 1999

[32] Rennison CM. Criminal victimization 1999: Changes 1998-1999 with trends 1993-1999. Washington DC: U.S. Government Printing Office 2000

[33] Rennison CM. Criminal victimization 2000: Changes 1999-2000 with trends 1993-2000. Washington DC: U.S. Government Printing Office 2001

[34] Rennison CM. Hispanic victims of violent crime 19932000/Víctimas Hispanas de crímenes violentos 1993-2000. Washington DC: U.S. Government Printing Office 2002a.
[35] Rennison CM. Criminal victimization 2001: Changes 2000-2001 with trends 1993-2001. Washington DC: U.S. Government Printing Office $2002 b$.

[36] Rennison CM, Rand MR. Criminal victimization 2002. Washington DC: U.S. Government Printing Office 2003.

[37] Ringel C. Criminal victimization: 1996 changes 1995-96 with trends 1993-96. Washington DC: U.S. Government Printing Office 1997.

[38] Fisher BS, Daigle LE, Cullen FT, Turner MG. Reporting sexual victimization to the police and others: Results from a national-level study of college women. Crim Justice Behavior 2003; 30: 6-38.

[39] Hubble DL. The National Crime Victimization Survey redesign: New questionnaire and procedures development and phase-in methodology. Paper presented at the annual meetings of the American Statistical Association Orlando FL. 1995.

[40] Rennison CM, Rand MR. Introduction to the National Crime Victimization Survey. In: Lynch JP, Addington LA. Eds. Understanding crime statistics: Revisiting the divergence of the NCVS and the UCR, Cambridge University Press 2007; pp. 17-54.

[41] Garofalo J. The National Crime Survey 1973-1986: Strengths and limitations of a very large data set. In: MacKenzie DL, Baunach PJ, Roberg, RR. Eds. Measuring crime: Large-scale long-range effort, State University of New York Press 1990; pp. 75-97.

[42] Rand MR. Criminal victimization 2008. Washington DC: U.S. Government Printing Office 2009

[43] Hindelang MJ. Variations in sex-race-age specific incidence rates of offending. Am Sociol Rev 1981; 46: 461-474.

[44] Rennison CM. Reporting to the police by Hispanic victims of violence. Violence Vict 2007; 22: 754-772.

[45] Hosmer DW, Lemeshow S. Applied logistic regression (2nd ed.), New York: Wiley 2000.

[46] Felson RB, Messner SF, Hoskin AH. Victim-offender relationship and calling the police in assaults. Criminology 1999; 37: 931-947.

[47] Brown B, Benedict WR. Perceptions of the police: Past findings methodological issues conceptual issues and policy implications. Policing 2002; 25: 543-580.

[48] Shusta RM, Levine DR, Harris PR, Wong HZ. Multicultural Law Enforcement $\left(2^{\text {nd }}\right.$ ed.). Upper Saddle River NJ: Pearson Education 2002.

[49] Cao L. Visible minorities and confidence in the police. Canadian Journal of Criminology and Criminal Justice 2011, January [Retrieved 2011 April 15] Available from http://0-find.galegroup. com.skyline.ucdenver.edu/gtx/retrieve.do? contentSet=IAC-Docum ents\&qrySerId=Locale $\% 28$ en $\% 2$ CUS $\% 2$ C $\% 29 \% 3 \mathrm{AFQE} \% 3 \mathrm{D} \% 28$ JN\%2CNone $\% 2$ C $54 \% 29 \% 22$ Canadian + Journal + of + Criminology+ and +Criminal + Justice $\% 22 \% 3$ AAnd $\% 3$ ALQE\%3D\%28DA\%2CNo ne $\% 2 \mathrm{C} 8 \% 2920110101 \% 24 \&$ inPS $=$ true $\&$ tabID $=$ T002 \&prodId $=\mathrm{AO}$ NE\&searchId=R1\&retrieveFormat $=$ PDF\&currentPosition $=2 \&$ user GroupName $=$ auraria_main\&resultListType $=$ RESULT_LIST\&sort $=$ DateDescend $\&$ docId $=$ A252004890\&noOfPages $=26$

[50] Garcia V, Cao L. Race and satisfaction with the police in a small city. J Crim Justice 2005; 33: 191-199.

[51] Sivasubramaniam D, Goodman-Delahunty J. Ethnicity and trust: Perceptions of police bias. Int J Police Sci Manag 2008; 10: 388401.

[52] Weitzer R, Tuch SA. Racially biased policing: Determinants of citizen perceptions. Soc Forces 2005; 83: 1009-1030.

[53] Taylor TJ, Turner KB, Esbensen F-A, Winfree LTJ. Coppin' an attitude: Attitudinal differences among juveniles toward police. J Crim Justice 2001; 29: 295-305.

[54] Ren L, Cao L, Lovrich N, Gaffney M. Linking confidence in the police with the performance of the police: Community policing can make a difference. J Crim Justice 2005; 33: 55-66. 